\title{
Cornish Cross Chicken
}

National Cancer Institute

\section{Source}

National Cancer Institute. Cornish Cross Chicken. NCI Thesaurus. Code C117981.

Derived from a cross between the commercial Cornish chicken and a White Plymouth Rock chicken, this breed grows rapidly and reaches 4-6 pounds in 6 weeks. 